\title{
A review on wax deposition issue and its impact on the operational factors in the crude oil pipeline
}

\author{
Ibrahim Elganidi, Basem Elarbe, Norida Ridzuan, Norhayati Abdullah* \\ Faculty of Chemical and Process Engineering Technology, College of Engineering Technology, University Malaysia Pahang, 26300 Gambang, \\ Pahang, Malaysia \\ * Corresponding author: yatiabdullah@ump.edu.my
}

Article history

Received 30 May 2020

Revised 14 September 2020

Accepted 22 October 2020

\begin{abstract}
The deposition of wax is a common occurrence affecting the flowability of crude oil, which happens at a temperature beneath the Wax Appearance Temperature. At this threshold, there is a gradual accumulation of crystals wax on the inner surface of pipelines. In this research, the previous studies on the effects of residence time, pressure, flow rate, crude oil composition, and temperature differential were carefully enumerated. On the overall, the differential temperature across the pipeline wall and crude oil inside it were considered as the most critical factor contributing to wax deposition. The result from different studies had argued out the effect of significant temperature differential as a leading cause of wax deposition reduction. Also, there is conflict among many researchers on whether the flow rate could result in a reduction in the amount and thickness of deposited wax. However, the wax deposition increases with an increasing resident time up to a particular time, after which the wax deposition experiences a downward trend. On the contrary, most researchers indicated that pressure is not a significant factor of wax deposition, but the conclusion that obtained through this research shows the opposite. Despite these, additional works are required in acquiring substantial results for more accurate as compared with the real-life crude oil flow in the pipeline.
\end{abstract}

Keywords: Crude Oil Composition; Flow Rate; Residence Time; Temperature Differential

\section{INTRODUCTION}

The crude oil is a complex mixture that comprises of different hydrocarbons such as aromatics, asphaltenes, resins, and paraffin waxes (Chen et al., 2009; Duarte et al., 2016; Kasumu et al., 2013). The midstream division of the oil and gas industry principally relies on the guaranteed flow of raw petroleum from upstream to the downstream segment containing a comprehensive range of hydrocarbon segments (Litvinets et al., 2016; Santos et al., 2014). Moreover, the issues of the flow assurance, for instance, hydrates (Chong et al., 2016; Daraboina et al., 2013), asphaltenes (Cenegy, 2001; Mullins, 2008), and wax deposition (Chi et al., 2016) have exposed critical problems that disturb transportation of the crude oil. The paraffin waxes are predominantly responsible for the process of wax deposition, which separated from the raw petroleum and start to aggregate on the internal surface of the transporting pipelines at a temperature below the Wax Appearance Temperature (WAT) (Al-Sabagh et al., 2017; Wang et al., 2003). The crystallization process of paraffin can lead to critical problems in the storage, production, and transportation because of loss in the flowing ability of crude oil as well as increasing in the crude oil viscosity and some cases lead to blockage in the pipeline (Al-Sabagh et al., 2009; Jung et al., 2011; Yao et al., 2016). The issue of wax deposition is a sophisticated and costly challenge for crude oil production and transportation, particularly in off sure oil field as the temperature of the seabed is about $40{ }^{\circ} \mathrm{F}$, (Huang et al., 2016; Wang et al., 2019) which affords a noteworthy thermal driving force for the wax to precipitate. These days, the offshore reservoirs represent practically fifty percent of the sedimentary basins, for instance, West Africa, the Gulf of Mexico, and China Sea (Aiyejina et al., 2011).

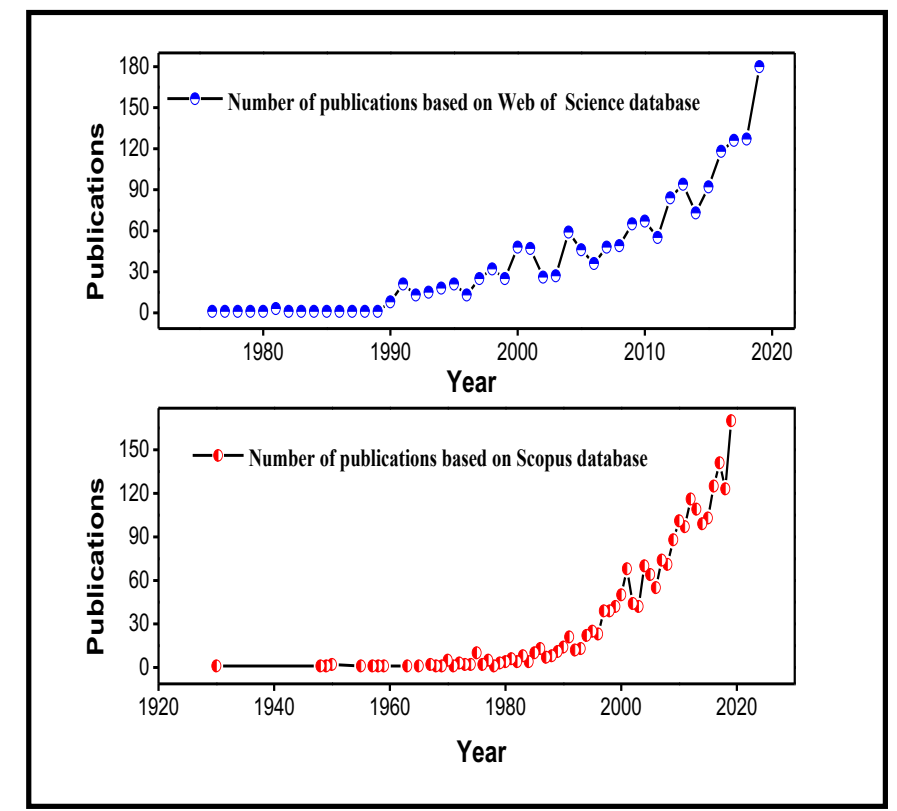

Fig. 1 Research publications on "Wax Deposition" based on data obtained from Scopus \& Web of Science database on February 1, 2020. 
As shown in Fig. 1, important consideration has been made on the wax deposition researches as time continues, the first recognition of wax deposition issue was in 1923 and mindfulness has been expanding exponentially from the 1980s as of recently. Accordingly, noteworthy expenses of OPEX and CAPEX has been consumed by oil organizations on the mitigation and prevention strategies to guarantee the crude oil flow (Chi et al., 2019). Therefore, agglomeration of wax is considered as the most significant challenge encountered in production, transportation, and refining of raw petroleum at lowtemperature ambient conditions (Akinyemi et al., 2016).

There are myriads of factors affecting the wax precipitation in the crude oil pipeline from the fluctuation of crude oil solubility in relation to temperature differentials. Additionally, other factors, such as the composition of the oil with existing solution gas and crude oil pressure, influences wax deposition in a crude oil pipeline, as reported by Zhu et al. (2008). Factors such as time, flow rate, thermal history, completion, and pipe or deposition surface roughness also impact on the deposition of wax in petroleum pipelines as explored by many researchers (Kasumu, 2014; Leontaritis and Geroulis, 2011; Nazar et al., 2005; Noville and Naveira, 2012; Tiwary and Mehrotra, 2008).

The main goal of this review is to deliver an overview of how the operating factors influence on the wax deposition issue in the crude oil pipeline. Even though significant study efforts have been expended on this subject, no satisfactory agreement has been achieved within the available literature. This review article will also touch on several points regarding how these factors control the wax deposition issue and understanding its future application.

\section{FACTORS AFFECTING WAX DEPOSITION}

This section lists and demonstrates the core factors that affect and control the wax deposition process in crude oil pipelines such as temperature differential, flow rate, experimental time, pressure, and crude oil composition.

\section{Temperature differential}

The depositions of wax on the pipeline wall took place when the temperature of crude oil declined below the wax appearance temperature. An increase in the temperature difference between the bulk solution and the cold surface of the wall leads to an increase in wax. The temperature differential is therefore considered as one of the most contributing factors influencing wax deposition in crude oil pipelines. According to Kelechukwu et al. (2010), an escalation in the temperature difference between the bulk solution and pipeline wall will lead to a corresponding reduction in the wax deposition. This was corroborated by Mahto and Kumar (2013), who reported a decline in the wax deposition with the rising temperature differential, as presented in Fig. 2.

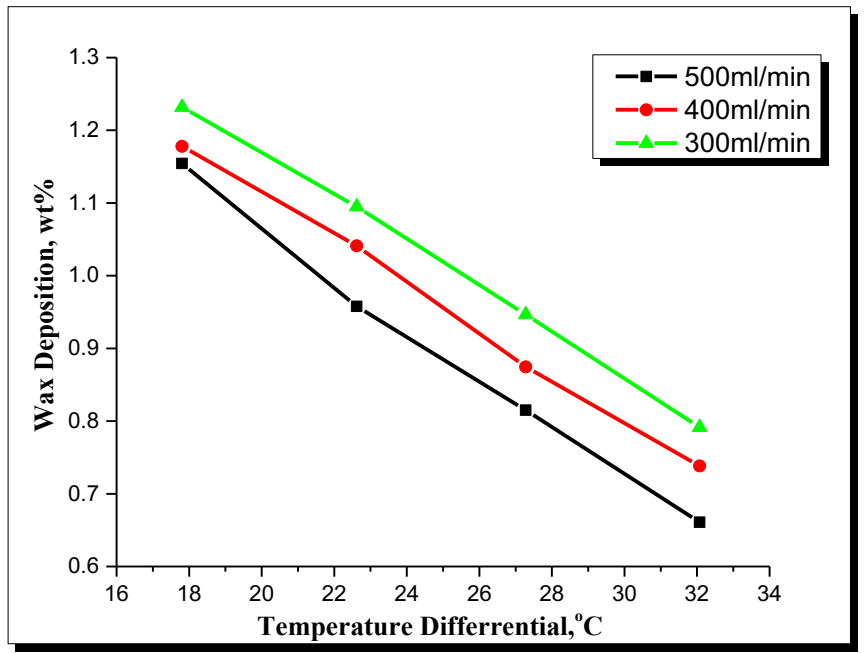

Fig. 2 The effect of temperature differential on wax deposition (Mahto and Kumar, 2013)
Moreover, a similar relationship was observed in previous studies between the deposition wax and difference in the temperature of the pipeline wall and crude oil (Bott and Gudmundsson, 1977; Haq, 1978; Wang et al., 2015).

However, these outcomes conflicted with what has been reported by who reported an increase in the precipitated wax when temperature difference in the increases (Kelechukwu et al., 2010; Mahto and Kumar, 2013).

The findings observed in this study reported previous studies that examined the decline in the crude oil temperature as wax deposition increases even when the temperature of crude is above the wax appearance temperature. Firstly, when the wax starts to precipitate on the pipeline wall, the rate of deposition is slightly high, nevertheless, after a while, the rate of wax deposition slows down, and the wax layer thickness will rise (Ahmed, 2018; Creek et al., 1999; Leontaritis, 2007).

Moreover, the wax is deposited in smaller and larger crystals, and this is due to the high availability of the crystallization positions at the higher cooling rate. The quantity and dimensions of the crystals formed are considered as a critical factor in a wax deposition.

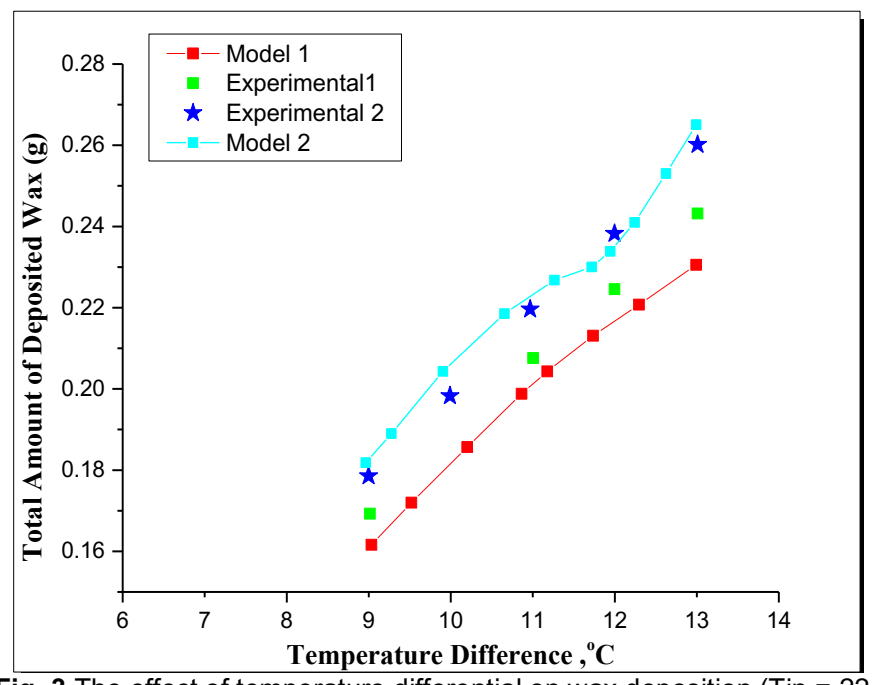

Fig. 3 The effect of temperature differential on wax deposition (Tin = 22 ${ }^{\circ} \mathrm{C}$, Time= 1 hour) (Nazar et al., 2005)

On the contrary, the procedure of crystallization is patterned orderly when the cooling rate is low, so the crystals formed are more orderly with characteristics free energy and surface area (Sanjay et al., 1995).

Kang et al. (2014) reported that the composition of the precipitated wax is affected by the temperature differential. Thus the cooling rate is higher when the temperature differential is high, and lower melting waxes crystallize concurrently, thus creating a weak, porous structure with the cavities full of oil, as illustrated in Fig. 3.

\section{Flow Rate}

The flow rate in the crude oil pipeline is another important affecting the wax deposition, as reported in previous studies (Kang et al., 2014). Many of them opined that the rate of wax deposition wax reduced as the flow rate in the pipeline increases, as illustrated in Fig. 4.

Furthermore, the viscosity of the deposited wax declined with an increasing flow rate during the isothermal condition, as pointed out by Perez (2002). Jennings and Weispfennig (2005) Investigated the impact of shear on wax deposition, and the results show a decrease in the precipitated wax. The results from Cabanillas et al. (2007) investigations demonstrated that in laminar flow, the thickness of the precipitated wax declined when the flow rate rises. Kelechukwu et al. (2010) concluded that rising the flow rate to turbulence flow leads to a gradual reduction in the deposited wax. Swivedi et al. (2013) noted that an increase in the shear stress leads to a reduction in the wax deposition thickness as corroborated by other researchers.

Additionally, a similar trend was enumerated by Mahto and Kumar (2013) at a steady-state level of temperature differential and resident time. The precipitation of wax rises with decreasing flow rate in the laminar flow, and this is due to the increase in the accessibility of the 
wax particles deposit on the surface. Whereas, the precipitated wax decline gradually when the flow rate changes to a turbulence flow because of the predominant shear dispersion in the turbulent flow phases as reported by Theyab (2018). This can be clarified based on viscous dragging, which rises due to the expanding speed of the liquid, which acts as a resistance force to the fluid flow. The viscous drag causes the wax precipitated layer to be less in thickness due to the increased shear stress.

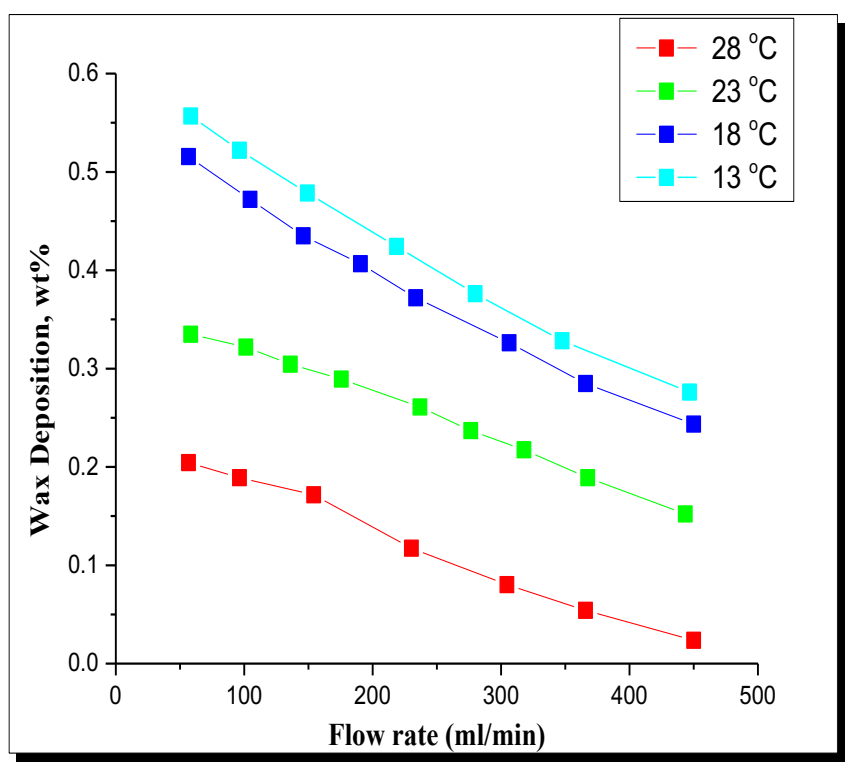

Fig. 4 The effect of flow rate on the wax deposition (Junyi and Hasan, 2018)

Jessen and Howell (1958) demonstrated that the rate of wax deposition differs with a flow rate, which attained the maximum quantity immediately as it changes to turbulent flow and then decreases when increasing the turbulent flow. Creek et al. (1999) opined that the deposition rate falls with increasing flow rate, rather than rising as indicated by present deposition simulation tools for turbulent and laminar flow. Nazar et al. (2005) reported that the amount of deposited wax increased due to an increase in the flow rate, and this continues until the critical flow rate is attained. Panacharoensawad and Sarica (2013) further indicated that the thickness of wax deposition during high flow rate could be thicker than the lower flow rate during the flow loop experiment. However, Kang et al. (2019a) reported that the increase in a wax deposition from an increase flow rate could be attributed to the volume of crude oil-injected containing an excess of wax, as presented in Fig. 5.

It can, therefore, be concluded that the wax crystals have the ability to stick on the pipeline wall because of their high cohesive properties. This invariably results in the breaking of crystals wax into little particles, which leads to a decrease in a wax deposition, thereby limiting its adhesion to the pipeline surface. On the contrary, wax crystals which adhere at high flow rate are relatively stiff and tightly coupled because wax crystals are able to adhere firmly on the pipe wall and so challenging to remove. In view of these, one may conclude that most of the existing researches demonstrated a decline in wax thickness as the flow rate increases even with the laminar flow.

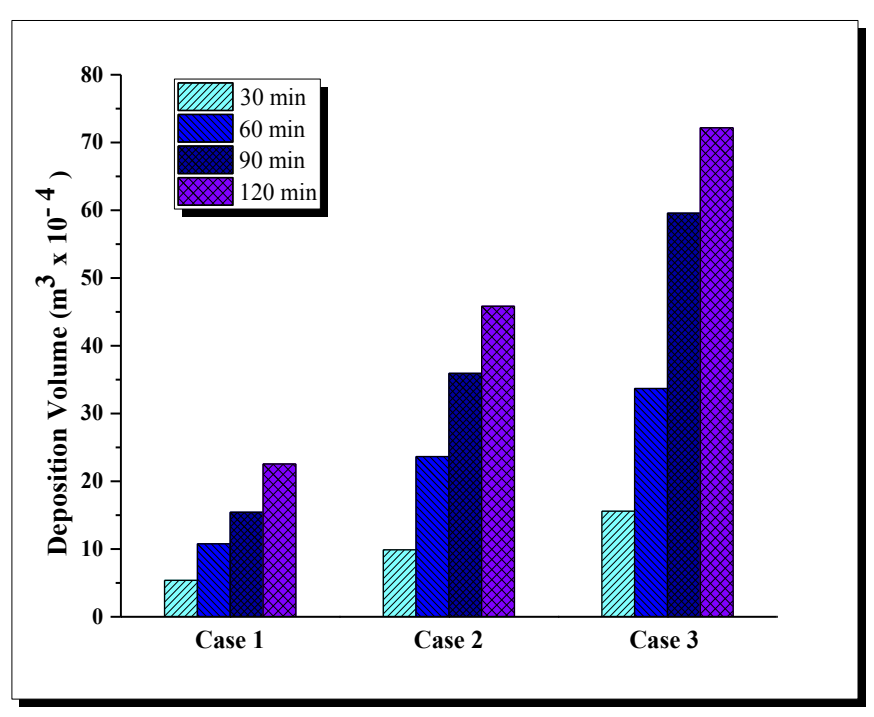

Fig. 5 Volume of wax deposition thickness based on the flow rate (Kang et al., 2019a)

\section{Experimental time}

The residence time for crude oil in pipelines is considered as one of the critical variables impacting the wax deposition. The wax deposition increases gradually throughout the two hours of examination, and this could be attributed to the fact that most of the liquefied paraffin in the oil is deposited on the pipeline surface. However, despite the decreasing amount of paraffin in the crude, the deposition of wax is expanded somewhat with a rise in the residence time (Hammami and Raines, 1997; Kasumu, 2014). Moreover, there is an insignificant rise in the mass of deposited wax after 4 hrs. of experimentation, and this is because the more significant part of the crude wax particles has precipitated on the pipeline wall (Kasumu, 2014; Tiwary and Mehrotra, 2008). Kelechukwu et al. (2010) reported that an increase in residence time leads to a corresponding increase in the wax deposition at a steadystate level (Fig. 6). However, the wax deposition continues until the number of deposited wax drops with increasing residence time. Additionally, the higher loss in temperature occurred due to the residence time, which made the wax to be stored on the pipe wall. Mahto and Kumar (2013) obtained a similar trend in their investigation at a high residence time. The above results are in agreement with previous studies (Bott and Gudmundsson, 1977; Haq, 1978; Junyi and Hasan, 2018; Towler and Rebbapragada, 2004). In the downstream section of the petroleum industry, the deposition of wax increases with a constant supply of fresh crude. Moreover, the majority of studies were conducted using the closed-loop system, and this indicated that there is no continuous flow of fresh crude oil through the pipeline. Therefore, after a longer residence time, the wax deposition will decrease due to thermal insulation from the wax deposition layers. The previous studies indicated that after $30 \mathrm{~min}$, the mixture attained a thermal pseudosteady state (Hoteit et al., 2008; Theyab, 2018).

\section{Pressure}

There is undeniable evidence that the crude oil is trapped inside reservoirs and transported through pipelines is done under high pressure, with the surrounding pressure of paramount importance (Aiyejina et al., 2011; Li et al., 2012). Due to the limitations of the existing measurement strategies, few studies considered the effects of high pressure on the flowability of crude oil (Velusamy et al., 2017; Webb et al., 2014). 


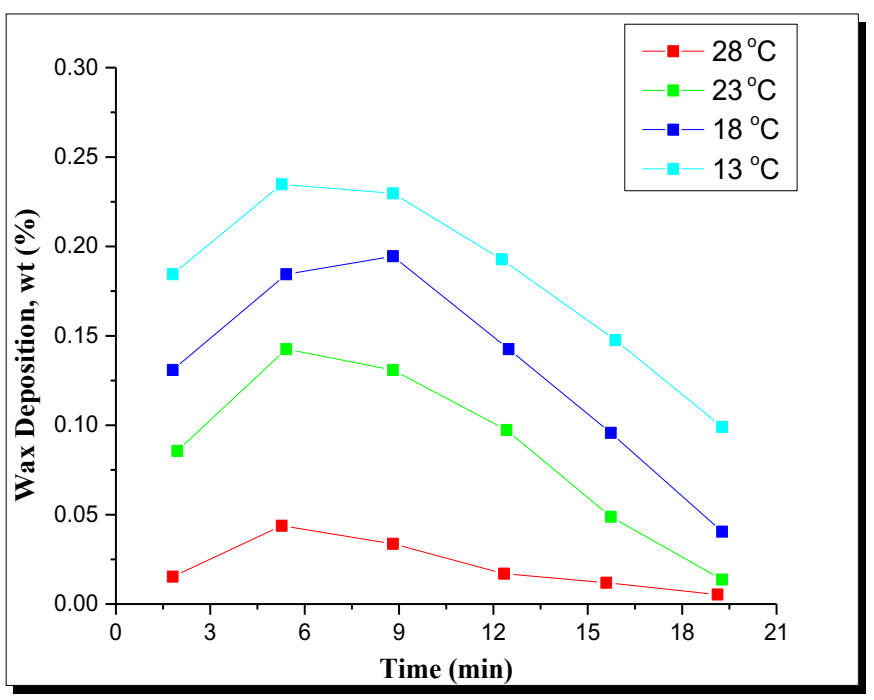

Fig. 6 The effect of time on wax deposition (Kelechukwu et al., 2010)

There is a pressure drop during the process of extracting crude oil from the reservoir, leaving behind light hydrocarbons. Kang et al. (2019b) reported that the deposited wax on the pipeline's inner wall rise the surface roughness and decreases the effective diameter while increasing the pressure loss. The wax appearance temperature (WAT) is typically distinctive for every crude oil sample, and this is subject to the composition and pressure of the crude.

In addition, crude oils are usually deposited in the reservoir or transported under high pressure in pipelines. The ambient pressure is also of greater significance in the event of deep oil spills (Li et al., 2012; Magda et al., 2013). Because of the limitations of the existing measuring techniques, few researches have been conducted on the flowability of oil at high pressure (Velusamy et al., 2017; Webb et al., 2014). As literature reports, during the transporting the crude oil under high pressure the oils demonstrate persistence and the modules rest rapidly. It shows that high pressure leads not only to the high viscosity of oils, but also to a non-Newtonian behaviour (Mortazavi-Manesh and Shaw, 2016). Furthermore, at atmospheric pressure, the cold flowability of crude oils and the effectiveness of chemical additives on the wax deposition, including the rheological and wax crystallizing characteristics, have been intensively researched to date. ( $\mathrm{Li}$ et al., 2011; Xu et al., 2013). Nevertheless, the effect of polymeric flow improvers on the flowability of crude oil has rarely been investigated under high-pressure condition. At ordinary pressure, polymeric additives that are active as a wax modifier or pour-point depressant (PPD) may combine with crystallized wax, disrupt the process of wax formation by preventing crystallized wax from being bound to large agglomerations.

Furthermore, the concentration of light hydrocarbons such as ethane, methane, and other gases like $\mathrm{CO}_{2}$ and $\mathrm{N}_{2}$ have a significant impact on the wax appearance temperature (WAT). These components act as solvents for wax in the crude oil. A drop in pressure results in the release of light hydrocarbon to the gaseous phase, which consequently results in a corresponding reduction in wax solubility due to the decline in light hydrocarbon. This results in wax precipitation on the pipeline wall due to pressure decrease (Kristine, 2012). However, most researchers indicated pressure as an insignificant factor responsible for wax deposition, particularly for crude oil stored in tanks and dead oil (Lashkarbolooki et al., 2010; Valinejad and Nazar, 2013). The effect of pressure should, therefore, not be neglected because it helps in raising the solubility of wax in the oil, leading to a decrease in the wax deposition (Theyab, 2018).

\section{Crude oil composition}

Crude oil is a complex mixture of different homogeneous organic compounds such as asphaltenes, aromatic, resins, saturated hydrocarbons, and other hetero-functionalized compounds like oxygen, nitrogen, and sulfur (Chen et al., 2018). Moreover, some substances derived from crude oil have been molecularly studie d. For instance, the aromatics compounds comprise several of very low polar hetero compounds, such as benzo thiophen, dibenzothiophenes, and dibenzofurans (Chen et al., 2018; Honse et al., 2012). Also, there are porphyrins and carboxylic acids in different groups of oxygen, nitrogen, and sulfur that are found in resin fractions (RamirezCorredores, 2017). However, Many researchers proved that the composition of crude oil as a significant factor affecting wax deposition in terms of viscosity and pour point reduction coupled with the concentration of light ends and paraffin in the crude (Gomez et al., 2013; Valinejad and Nazar, 2013). The presence of water in the crude composition has, therefore, been observed to reduce wax deposition, (Couto et al., 2008; Li et al., 1997). The molecules in crude oil can be divided into light and heavy molecules. The light particles are usually responsible for the formation of solid hydrate, while massive particles such as iso-paraffins and linear alkanes change phase into macro and microcrystalline solid (Theyab, 2018). Hence, crude oil composition impact on the structure and morphology of wax crystals (Yi and Zhang, 2011).

Since waxy crude has the capability to produce waxy crystals, the transport of crude oil is highly difficult due to the presence of a crystalline solid layer. In general, a sample of crude oil that contains over $5 \%$ wax is referred to as a waxy oil and the researches shows that only $2-4 \%$ wax is enough to form waxy crystals at temperatures beneath WAT of the sample (Zhang and Liu, 2008). The crude oil composition is made of varying rheological features such as pour point and viscosity, to varying degrees from the low temperature. The wax crystals will precipitate out of crude oil if the temperature drops to a certain degree. Wax crystals are fused into a 3-D network structure, the fluid components of crude oil are enclosed, thereby worsening, or even losing fluidity of crude oil (Chen et al., 2013). Hydrogen bonds between molecules of resin and asphaltenes are the average relative molecular mass of the largest and most polar components in crude oil which is responsible for high viscosity of crude, making it more complex to extract and transport crude oil (Chen et al., 2013). Asphaltenes considered as one of the polar and heaviest compounds in crude oil consisting of fused polynuclear flavourings, alkyl chains, and heavy metals like Nickel and Vanadium, with the highest degree of aromaticity and polarity. In addition, asphaltenes are available in threedimensional form because of strong intermolecular forces like $\pi$ bonding and hydrogen bonding interaction (Murgich, 2002). The relationship between crude oil components is very critical for the transportation and exploitation of crude oil. Therefore, if the interaction between the crude oil compounds has been studied clearly, the producer may foresee the crude oil flow and precipitation of wax, thus avoiding poor fluidity issues of crude oil and taking timely preventive steps. Nevertheless, insufficient studies have been done on the interface of crude oil elements, in particular the impact of crude oil compounds on the crystallization of crude oil waxes.

\section{CONCLUSION}

A detailed literature review on the operating factors influencing the wax deposition in the pipeline has been carefully enumerated in this study. Factors such as temperature differential, residence time, pressure, flow rate, and crude oil composition were discussed. It has been concluded that the temperature differential between the crude oil and pipeline is the most critical factor in a wax deposition. However, there is 1 uncertainty as to whether temperature differential and flow rate increase could lead to a decline in the wax deposition.

Moreover, as the residence time escalations, the amount of wax deposition increases until it reaches a critical peak value before experiencing a steady decline. Additionally, the crude oil composition factor affects the structure and morphology of the wax crystals may, and this is because of the accumulation of some light and heavy molecules. Finally, the pressure was not considered as a significant factor responsible for the deposition of wax, most notably for dead oil in storage tanks. However, the impact of the pressure on the deposition of wax should not be ignored; this is because the pressure helps in raising the wax solubility in the oil, leading to a reduction in a wax 
deposition. Further studies are therefore recommended in order to achieve an accurate result comparable with the real-life flow of crude in the pipeline.

\section{ACKNOWLEDGMENT}

Authors acknowledge the financial support of this research from Faculty of Chemical and Process Engineering Technology at University Malaysia Pahang utilizing PGRS 1903103 scheme.

\section{REFERENCES}

Ahmed, I. M. (2018). Modeling and development of insulation materials in subsea pipelines. Memorial University of Newfoundland.

Aiyejina, A., Chakrabarti, D. P., Pilgrim, A., and Sastry, M. (2011). Wax formation in oil pipelines: A critical review. International journal of multiphase flow, 37(7), 671-694.

Akinyemi, O. P., Udonne, J. D., Efeovbokhan, V. E., and Ayoola, A. A. (2016). A study on the use of plant seed oils, triethanolamine and xylene as flow improvers of Nigerian waxy crude oil. Journal of applied research and technology, 14(3), 195-205.

Al-Sabagh, A., El-Din, M. N., Morsi, R., and Elsabee, M. (2009). Styrenemaleic anhydride copolymer esters as flow improvers of waxy crude oil. Journal of Petroleum Science and Engineering, 65(3-4), 139-146.

Al-Sabagh, A., Khidr, T., Moustafa, H., Mishrif, M., and Al-Damasy, M. (2017). Synergistic effect between surfactants and polyacrylates-maleicanhydride copolymers to improve the flow properties of waxy crude oil. Journal of Dispersion Science and Technology, 38(7), 1055-1062.

Bott, T., and Gudmundsson, J. (1977). Deposition of paraffin wax from kerosene in cooled heat exchanger tubes. The Canadian Journal of Chemical Engineering, 55(4), 381-385.

Cabanillas, J., Leiroz, A., and Azevedo, L. (2007). Paraffin Deposition in Laminar Channel Flow, in the Presence of Suspended Crystals. Paper presented at the Proceedings of the 19th International Congress of Mechanical Engineering, 5-9.

Cenegy, L. M. (2001). Survey of successful world-wide asphaltene inhibitor treatments in oil production fields. Paper presented at the SPE Annual Technical Conference and Exhibition.

Chen, G., Li, X., and Zhang, J. (2013). Mechanism of the Effect of Components Interaction on Wax Precipitation Process in Crude Oil. Acta Petrolei Sinica (Petroleum Processing Section)(5), 18.

Chen, G., Lin, J., Hu, W., Cheng, C., Gu, X., Du, W., et al. (2018). Characteristics of a crude oil composition and its in situ waxing inhibition behavior. Fuel, 218, 213-217.

Chen, W., Zhang, X., Zhao, Z., and Yin, C. (2009). UNIQUAC model for wax solution with pour point depressant. Fluid Phase Equilibria, 280(1-2), 9-15.

Chi, Y., Daraboina, N., and Sarica, C. (2016). Investigation of inhibitors efficacy in wax deposition mitigation using a laboratory scale flow loop. AIChE Journal, 62(11), 4131-4139.

Chi, Y., Yang, J., Sarica, C., and Daraboina, N. (2019). A critical review of controlling paraffin deposition in production lines using chemicals. Energy \& fuels, 33(4), 2797-2809.

Chong, Z. R., Yang, S. H. B., Babu, P., Linga, P., and Li, X.-S. (2016). Review of natural gas hydrates as an energy resource: Prospects and challenges. Applied energy, 162, 1633-1652.

Couto, G. H., Chen, H., Delle-case, E., Sarica, C., and Volk, M. (2008). An Investigation of Two-Phase Oil/Water Paraffin Deposition. SPE Production \& Operations, 23(01), 49-55.

Creek, J., Lund, H. J., Brill, J. P., and Volk, M. (1999). Wax deposition in single phase flow. Fluid Phase Equilibria, 158, 801-811.

Daraboina, N., Malmos, C., and von Solms, N. (2013). Synergistic kinetic inhibition of natural gas hydrate formation. Fuel, 108, 749-757.

Duarte, L. M., Filgueiras, P. R., Silva, S. R., Dias, J. C., Oliveira, L. M., Castro, E. V., et al. (2016). Determination of some physicochemical properties in Brazilian crude oil by $1 \mathrm{H}$ NMR spectroscopy associated to chemometric approach. Fuel, 181, 660-669.

Gomez, S., Pena, J. L. H., Duenas-Diez, M. H., and Merino-Garcia, D. (2013). Risk Assessment Methodology for Flow Assurance Challenges: The Sooner You Look at it, the Better. Paper presented at the OTC Brasil.

Hammami, A., and Raines, M. A. (1997). Paraffin deposition from crude oils: comparison of laboratory results to field data. Paper presented at the SPE Annual Technical Conference and Exhibition.

Haq, M. A. (1978). Deposition of paraffin wax from its solution with hydrocarbons (USMS 10541). Society of Petroleum Engineers.
Honse, S. O., Ferreira, S. R., Mansur, C. R., Lucas, E. F., and González, G. (2012). Separation and characterization of asphaltenic subfractions. Química Nova, 35(10), 1991-1994.

Hoteit, H., Banki, R., and Firoozabadi, A. (2008). Wax deposition and aging in flowlines from irreversible thermodynamics. Energy \& Fuels, 22(4), 26932706.

Huang, Z., Zheng, S., and Fogler, H. S. (2016). Wax deposition: experimental characterizations, theoretical modeling, and field practices: CRC Press.

Jennings, D. W., and Weispfennig, K. (2005). Effects of shear and temperature on wax deposition: Coldfinger investigation with a Gulf of Mexico crude oil. Energy \& fuels, 19(4), 1376-1386.

Jessen, F., and Howell, J. N. (1958). Effect of flow rate on paraffin accumulation in plastic, steel, and coated pipe.

Jung, K. M., Chun, B. H., Park, S. H., Lee, C. H., and Kim, S. H. (2011). Synthesis of methacrylate copolymers and their effects as pour point depressants for lubricant oil. Journal of applied polymer science, 120(5), 2579-2586.

Junyi, K., and Hasan, N. (2018). Review of the Factors that Influence the Condition of Wax Deposition in Subsea Pipelines.

Kang, P.-S., Hwang, J. Y., and Lim, J.-S. (2019a). Flow Rate Effect on Wax Deposition Behavior in Single-Phase Laminar Flow. Journal of Energy Resources Technology, 141(3), 032903.

Kang, P.-S., Hwang, J. Y., and Lim, J.-S. (2019b). Flow Rate Effect on Wax Deposition Behavior in Single-Phase Laminar Flow. Journal of Energy Resources Technology, 141(3).

Kang, P.-S., Lee, D.-G., and Lim, J.-S. (2014). Status of wax mitigation technologies in offshore oil production. Paper presented at the The Twentyfourth International Ocean and Polar Engineering Conference.

Kasumu, A. S. (2014). An investigation of solids deposition from two-phase wax-solvent-water mixtures. University of Calgary.

Kasumu, A. S., Arumugam, S., and Mehrotra, A. K. (2013). Effect of cooling rate on the wax precipitation temperature of "waxy" mixtures. Fuel, 103, 1144-1147.

Kelechukwu, E. M., Al Salim, H. S. S., and Yassin, A. A. M. (2010). Influencing factors governing paraffin wax deposition during crude production. International Journal of Physical Sciences, 5(15), 2351-2362.

Kristine, A. (2012). pour point depressant development through experimental design. Unpublished Master Thesise, University of Stavanger, Norway.

Lashkarbolooki, M., Seyfaee, A., Esmaeilzadeh, F., and Mowla, D. (2010). Experimental investigation of wax deposition in Kermanshah crude oil through a monitored flow loop apparatus. Energy \& fuels, 24(2), 1234-1241.

Leontaritis, K. J. (2007). Wax Flow Assurance Issues in Gas Condensate Multiphase Flowlines. Paper presented at the Offshore Technology Conference.

Leontaritis, K. J., and Geroulis, E. (2011). Wax Deposition CorrelationApplication in Multiphase Wax Deposition Models. Paper presented at the Offshore Technology Conference.

Li, K., McAlpin, C. R., Akeredolu, B. A., Bazyleva, A., Voorhees, K. J., Evans, R. J., et al. (2012). A rheological and chemical investigation of Canadian heavy oils from the McMurray formation. Energy \& fuels, 26(7), 44454453.

Li, L., Guo, X., Adamson, D. H., Pethica, B. A., Huang, J. S., and Prud'homme, R. K. (2011). Flow improvement of waxy oils by modulating long-chain paraffin crystallization with comb polymers: an observation by X-ray diffraction. Industrial \& engineering chemistry research, 50(1), 316-321.

Li, M., Su, J., Wu, Z., Yang, Y., and Ji, S. (1997). Study of the mechanisms of wax prevention in a pipeline with glass inner layer. Colloids and Surfaces A: Physicochemical and Engineering Aspects, 123, 635-649.

Litvinets, I. V., Prozorova, I. V., Yudina, N. V., Kazantsev, O. A., and Sivokhin, A. P. (2016). Effect of ammonium-containing polyalkyl acrylate on the rheological properties of crude oils with different ratio of resins and waxes. Journal of Petroleum Science and Engineering, 146, 96-102.

Magda, J. J., Elmadhoun, A., Wall, P., Jemmett, M., Deo, M. D., Greenhill, K. L., et al. (2013). Evolution of the pressure profile during the gelation and restart of a model waxy crude oil. Energy \& fuels, 27(4), 1909-1913.

Mahto, V., and Kumar, A. (2013). Effect of several parameters on wax deposition in the flow line due to Indian waxy crude oil. Int J Appl Eng Res Dev, 3(4), 1-10.

Mortazavi-Manesh, S., and Shaw, J. M. (2016). Effect of pressure on the rheological properties of Maya crude oil. Energy \& Fuels, 30(2), 759-765.

Mullins, O. C. (2008). Review of the molecular structure and aggregation of asphaltenes and petroleomics. Spe Journal, 13(01), 48-57.

Murgich, J. (2002). Intermolecular forces in aggregates of asphaltenes and resins. Petroleum science and technology, 20(9-10), 983-997.

Nazar, A. S., Dabir, B., and Islam, M. (2005). Experimental and mathematical modeling of wax deposition and propagation in pipes transporting crude oil. Energy sources, 27(1-2), 185-207. 
Noville, I., and Naveira, L. (2012). Comparison between real field data and the results of wax deposition simulation. Paper presented at the SPE Latin America and Caribbean Petroleum Engineering Conference.

Panacharoensawad, E., and Sarica, C. (2013). Experimental study of singlephase and two-phase water-in-crude-oil dispersed flow wax deposition in a mini pilot-scale flow loop. Energy \& Fuels, 27(9), 5036-5053.

Perez, O. C. H. (2002). Investigation of single-phase paraffin deposition characteristics. University of Tulsa.

Ramirez-Corredores, M. M. (2017). The science and technology of unconventional oils: finding refining opportunities: Academic press.

Sanjay, M., Simanta, B., and Kulwant, S. (1995). Paraffin problems in crude oil production and transportation: a review. SPE Production \& facilities, $10(01), 50-54$.

Santos, R., Loh, W., Bannwart, A., and Trevisan, O. (2014). An overview of heavy oil properties and its recovery and transportation methods. Brazilian Journal of Chemical Engineering, 31(3), 571-590.

Swivedi, P., Sarica, C., and Shang, W. (2013). Experimental Study on WaxDeposition Characteristics of a Waxy Crude Oil Under Single-Phase Turbulent-Flow Conditions. Oil and Gas Facilities, 2(04), 61-73.

Theyab, M. (2018). Wax deposition process: mechanisms, affecting factors and mitigation methods. Open Access $J$ Sci, 2(2), 112-118.

Tiwary, R., and Mehrotra, A. K. (2008). Deposition from wax- solvent mixtures under turbulent flow: Effects of shear rate and time on deposit properties. Energy \& Fuels, 23(3), 1299-1310.

Towler, B. F., and Rebbapragada, S. (2004). Mitigation of paraffin wax deposition in cretaceous crude oils of Wyoming. Journal of Petroleum Science and Engineering, 45(1-2), 11-19.

Valinejad, R., and Nazar, A. R. S. (2013). An experimental design approach for investigating the effects of operating factors on the wax deposition in pipelines. Fuel, 106, 843-850.

Velusamy, S., Sakthivel, S., and Sangwai, J. S. (2017). Effects of imidazoliumbased ionic liquids on the rheological behavior of heavy crude oil under high-pressure and high-temperature conditions. Energy \& Fuels, 31(8), 8764-8775.

Wang, K.-S., Wu, C.-H., Creek, J. L., Shuler, P. J., and Tang, Y. (2003) Evaluation of effects of selected wax inhibitors on paraffin deposition. Petroleum science and technology, 21(3-4), 369-379.

Wang, W., Huang, Q., Wang, C., Li, S., Qu, W., Zhao, J., et al. (2015). Effect of operating conditions on wax deposition in a laboratory flow loop characterized with DSC technique. Journal of Thermal Analysis and Calorimetry, 119(1), 471-485.

Wang, Z., Yu, J., Zhang, J., Liu, S., Gao, Y., Xiang, H., et al. (2019). Improved thermal model considering hydrate formation and deposition in gasdominated systems with free water. Fuel, 236, 870-879.

Webb, E. B., Koh, C. A., and Liberatore, M. W. (2014). High pressure rheology of hydrate slurries formed from water-in-mineral oil emulsions. Industrial \& Engineering Chemistry Research, 53(17), 6998-7007.

Xu, J., Xing, S., Qian, H., Chen, S., Wei, X., Zhang, R., et al. (2013). Effect of polar/nonpolar groups in comb-type copolymers on cold flowability and paraffin crystallization of waxy oils. Fuel, 103, 600-605.

Yao, B., Li, C., Yang, F., Zhang, Y., Xiao, Z., and Sun, G. (2016). Structural properties of gelled Changqing waxy crude oil benefitted with nanocomposite pour point depressant. Fuel, 184, 544-554.

Yi, S., and Zhang, J. (2011). Relationship between waxy crude oil composition and change in the morphology and structure of wax crystals induced by pour-point-depressant beneficiation. Energy \& Fuels, 25(4), 1686-1696.

Zhang, J.-j., and Liu, X. (2008). Some advances in crude oil rheology and its application. Journal of Central South University of Technology, 15(1), 288292.

Zhu, T., Walker, J. A., and Liang, J. (2008). Evaluation of wax deposition and its control during production of Alaska north slope oils: University of Alaskao. Document Number) 